\title{
Research on influence of gear parameters on noise, vibrations and harshness conditions for automatic transmissions run-off cycle
}

\author{
Nelu Pascalau ${ }^{1}$, Ioan Vuscan, Nicolae Panc ${ }^{1, *}$ \\ ${ }^{1}$ Technical University of Cluj-Napoca, Department of Manufacturing Engineering, 103-105 no. Bvd. \\ Muncii, Cluj-Napoca, Romania
}

\begin{abstract}
Noise vibration harshness $(\mathrm{NVH})$ defines, as a whole, that specific field within automotive industry, that studies mostly the noise and vibrations for different assemblies (such as chassis or drivetrain - gearbox) or complete vehicles, particularly cars and trucks. Gear quality parameters have been studied and it has been experienced that these parameters have an important relevance for NVH topic. Therefore, this paper introduces a case-study, as to highlight the influence of two of these parameters, profile angle deviation $(\mathrm{fH} \alpha)$ and tooth trace angle deviation $(\mathrm{fH} \beta)$, on run-off cycle on test benches, for high-performance automatic transmission, designed for passenger vehicles. The demand for high accuracy is mandatory, so fine adjustments are required, as could be further observed, in order to accomplish the requirements for a lower NVH run-off rate, while the whole life-time.
\end{abstract}

\section{Introduction}

Quality of a gear, highlighted by its elements, is defined by the accuracy of applied manufacturing processes, as to achieve the geometrical and dimensional demands, required by functional conditions and using cycles, for each component of an assembly or subassembly [1]. The influence of machining accuracy of gear parameters on noise vibration harshness conditions has been tested and experienced, therefore, it can be observed that, in order to reduce the level of noise and vibrations, it is important not only the machining accuracy, but also the fine adjustment of some parameters, as to ensure a smooth gearing process, concerning the complexity of brand-new automatic transmissions [2].

Decreasing the level of noise and vibrations while run-off cycle is a very important aspect within the automotive industry, therefore huge amounts of money are invested yearly, in order to develop new products and to optimize those in using cycle, as a result of the problems noted after a time range in use [3-6].

The sources of noise in a vehicle may vary, including the engine, drivetrain, contact between tires \& rolling surface and air friction, while moving [7]. Decreasing the NVH values has been and still is further studied, as a field apart within automotive industry.

* Corresponding author: nicolae.panc@.tcm.utcluj.ro 
A variety of specific solutions, combined with innovative simulation and competitive manufacturing technologies, ensures the wide range of solutions for products and systems. Sound insulation, as well as lowering the level of noise and vibrations, using special materials and combining some frequency ranges between 20 and $20.000 \mathrm{~Hz}$ is possible nowadays [8]. Speaking about assemblies and subassemblies, the problem is being specifically applied, related to final values required by the assembly itself, as not to exceed the level of noise \& vibrations [1]. This paper presents a case study, where the maximum limit for noise is $40 \mathrm{~dB}$, value registered on final assembly test bench, while run-off test cycle.

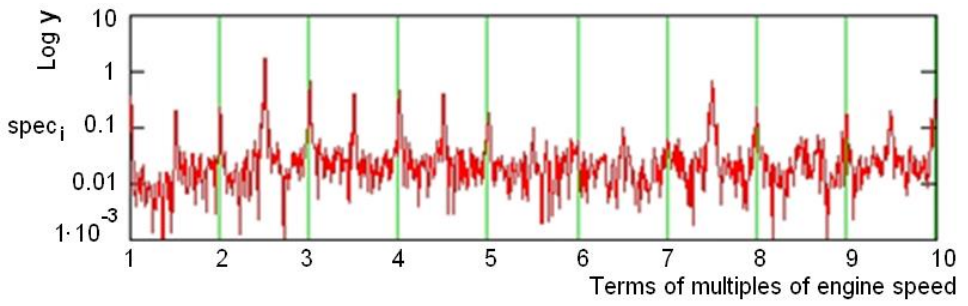

Fig. 1. The noise spectrum of Michael Schumacher's Ferrari at $16680 \mathrm{rpm}$, showing the various harmonics [9].

In order to measure the level of noise and vibrations for automatic transmissions (figure 1), there are used high performance test benches, similar to that one from figure 2, allowing functional simulation in real conditions, as well as measurement and registering of achieved values and identifying those components that produce disturbances while running.

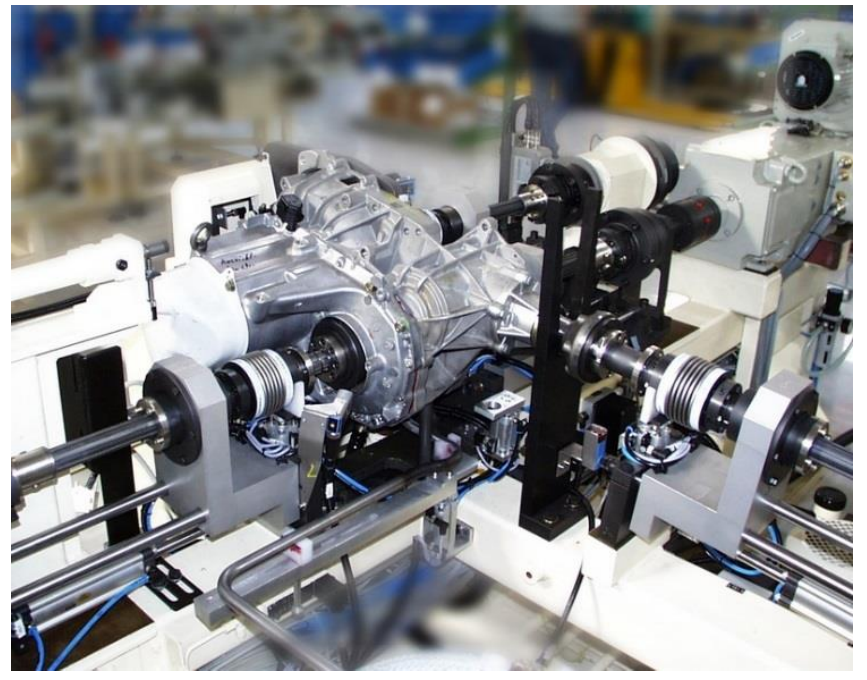

Fig. 2. Test bench for transmission run-off test [10].

Further on, there is described how exactly this research has been performed, through fine adjustment within manufacturing process of two parameters, profile angle deviation$\mathrm{fH} \alpha$ and tooth trace angle deviation- $\mathrm{fH} \beta$, as to get the desired results for noise level at the end of assembly process, in different cases, meaning different values set while gear hobbing process for single parts, in order to reach the demands for the whole assembly, during complex gearing process, inside the automatic transmission. 


\section{Research methodology}

The purpose of this case study is to highlight the influence of fine adjustment of these 2 parameters, $\mathrm{fH} \alpha$ and $\mathrm{fH} \beta$, on transmission run-off cycle, through gearing process with matting gears, ring gears and sun gears. In order to respect the maximum allowed limit for noise of $40 \mathrm{~dB}$ of the whole assembly, the quality requirements for gear manufacturing process are according to Q7, DIN 3962 [11].

Table 1 contents the parameters of gear hobbing process, performed on Gleason Pfauter P90 machines.

Table 1. Gear hobbing process parameters.

\begin{tabular}{|c|c|c|c|c|c|}
\hline Equipment & \multicolumn{5}{|c|}{ Process parameters } \\
\hline \multirow{3}{*}{$\begin{array}{c}\text { Gleason Pfauter } \\
\text { P90 }\end{array}$} & \multicolumn{2}{|c|}{ Roughing } & \multicolumn{2}{|c|}{ Finishing } & Cutting tool \\
\hline & Axial feed & $\begin{array}{l}\text { Cutting } \\
\text { speed }\end{array}$ & Axial feed & $\begin{array}{l}\text { Cutting } \\
\text { speed }\end{array}$ & \multirow{2}{*}{$\begin{array}{c}\text { HM, accuracy } \\
\text { AAA }+, 2 \text { starts, } \\
\text { DIN } 3960\end{array}$} \\
\hline & $\begin{array}{c}2.0 \\
\mathrm{~mm} / \mathrm{rev}\end{array}$ & $320 \mathrm{~m} / \mathrm{min}$ & $\begin{array}{c}0.4 \\
\mathrm{~mm} / \mathrm{rot}\end{array}$ & $850 \mathrm{~m} / \mathrm{min}$ & \\
\hline
\end{tabular}

As can be noticed in table 1, while gear hobbing process, the work-piece is also finished, according to required accuracy class, so the two parameters $\mathrm{fH} \alpha$ and $\mathrm{fH} \beta$ will be set as to avoid as much as possible the distortions from hardening process (figure 3).

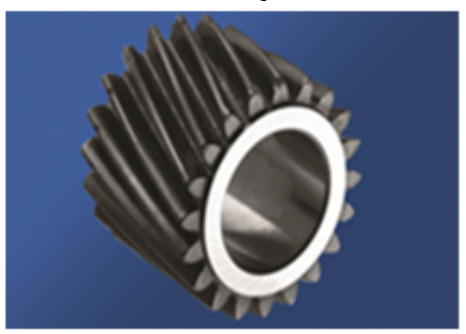

\begin{tabular}{ll} 
Quality after DIN 3962 & $=7$ \\
Deviation & \\
Profile form - & 0.009 \\
\hline Pressure angle - fHalfa & 0.007 \\
\hline Total pitch error - & 0.028 \\
Pitch error & 0.011 \\
Normal base pitch - & 0.009 \\
\hline Tooth-trace deviation- fHbeta & 0.011 \\
\hline
\end{tabular}

Fig. 3. Quality requirements for planetary gear.

The tests have been performed at the end of assembly process and have been identified 3 different cases, concerning the two parameters, $\mathrm{fH} \alpha \& \mathrm{fH} \beta$, as can be seen in tables 2,3 and 4. Basically, these tables content the individual values and average for these two parameters, for gear hobbing and finished part, as well.

Case 1, according to table 2:

- $\mathrm{fH} \alpha$ not optimized

- $\mathrm{fH} \beta$ not optimized

Table 2. Case $1-\mathrm{fH} \alpha$ and $\mathrm{fH} \beta$ not optimized.

\begin{tabular}{|c|c|c|c|c|c|c|c|}
\hline \multicolumn{4}{|c|}{ Gear hobbing } & \multicolumn{4}{c|}{ Finished } \\
\hline $\mathrm{fH} \alpha$ & $\mathrm{fH} \alpha \mathrm{m}$ & $\mathrm{fH} \beta$ & $\mathrm{fH} \beta \mathrm{m}$ & $\mathrm{fH} \alpha$ & $\mathrm{fH} \alpha \mathrm{m}$ & $\mathrm{fH} \beta$ & $\mathrm{fH} \beta \mathrm{m}$ \\
\hline$-3 / 11 \mu \mathrm{m}$ & $6 / 8 \mu \mathrm{m}$ & $6 / 18 \mu \mathrm{m}$ & $10 / 12 \mu \mathrm{m}$ & $-7 / 7 \mu \mathrm{m}$ & $-1 / 3 \mu \mathrm{m}$ & $-11 / 11 \mu \mathrm{m}$ & $-2 / 2 \mu \mathrm{m}$ \\
\hline
\end{tabular}

Further on, there is presented the case when $\mathrm{fH} \beta$ has been optimized, meaning asymmetrical adjustment on the right and left flank, $\mathrm{fH} \alpha$ not optimized.

Case 2, according to table 3:

- $\mathrm{fH} \alpha$ not optimized

- $\mathrm{fH} \beta$ optimized 
Table 3. Case $2-\mathrm{fH} \beta$ is opzimized.

\begin{tabular}{|c|c|c|c|c|c|c|c|}
\hline \multicolumn{4}{|c|}{ Gear hobbing } & \multicolumn{4}{c|}{ Finished } \\
\hline $\mathrm{fH} \alpha$ & $\mathrm{fH} \alpha \mathrm{m}$ & $\mathrm{fH} \beta$ & $\mathrm{fH} \beta \mathrm{m}$ & $\mathrm{fH} \alpha$ & $\mathrm{fH} \alpha \mathrm{m}$ & $\mathrm{fH} \beta$ & $\mathrm{fH} \beta \mathrm{m}$ \\
\hline $\begin{array}{c}-3 / 11 \\
\mu \mathrm{m}\end{array}$ & $\begin{array}{c}6 / 8 \\
\mathrm{~m}\end{array}$ & $\begin{array}{c}8 / 18 \mu \mathrm{m} \mathrm{left} \\
14 / 24 \mu \mathrm{m} \\
\text { right }\end{array}$ & $\begin{array}{c}11 / 13 \mu \mathrm{m} \text { left } \\
18 / 20 \mu \mathrm{m} \\
\text { right }\end{array}$ & $\begin{array}{c}-7 / 7 \\
\mu \mathrm{m}\end{array}$ & $\begin{array}{c}-1 / 3 \\
\mu \mathrm{m}\end{array}$ & $\begin{array}{c}-11 / 11 \\
\mu \mathrm{m}\end{array}$ & $\begin{array}{c}5 / 7 \mu \mathrm{m} \text { left } \\
8 / 10 \mu \mathrm{m} \\
\text { right }\end{array}$ \\
\hline
\end{tabular}

The last case, number 3 , it is about both parameters optimized, as it can be noticed in table number 4 .

Case 3, according to table 4:

- $\mathrm{fH} \alpha$ is optimized

- $\mathrm{fH} \beta$ is optimized

Table 4. Case $3-\mathrm{fH} \alpha$ and $\mathrm{fH} \beta$ are optimized.

\begin{tabular}{|c|c|c|c|c|c|c|c|}
\hline \multicolumn{4}{|c|}{ Gear hobbing } & \multicolumn{4}{c|}{ Finished } \\
\hline $\mathrm{fH} \alpha$ & $\mathrm{fH} \alpha \mathrm{m}$ & $\mathrm{fH} \beta$ & $\mathrm{fH} \beta \mathrm{m}$ & $\mathrm{fH} \alpha$ & $\mathrm{fH} \alpha \mathrm{m}$ & $\mathrm{fH} \beta$ & $\mathrm{fH} \beta \mathrm{m}$ \\
\hline $0 / 4$ & $1 / 3$ & $\begin{array}{c}8 / 18 \mu \mathrm{m} \text { left } \\
14 / 24 \mu \mathrm{m} \\
\text { right }\end{array}$ & $\begin{array}{c}11 / 13 \mu \mathrm{m} \text { left } \\
18 / 20 \mu \mathrm{m} \\
\text { right }\end{array}$ & $\begin{array}{c}-7 / 7 \\
\mu \mathrm{m}\end{array}$ & $\begin{array}{c}-6 /-1 \\
\mu \mathrm{m}\end{array}$ & $\begin{array}{c}-11 / 11 \\
\mu \mathrm{m}\end{array}$ & $\begin{array}{c}5 / 7 \mu \mathrm{m} \text { left } \\
8 / 10 \mu \mathrm{m} \\
\text { right }\end{array}$ \\
\hline
\end{tabular}

These values have been established after testing several charges of planetary gears, as to reach the capability of manufacturing and assembly processes. These fine adjustments have been performed based on results registered on transmission test bench at the end of assembly process.

\section{Results}

Within this chapter are presented the results achieved for each case, from the three presented above. These planetary gears are assembled in the automatic transmission, presented in figure 4.

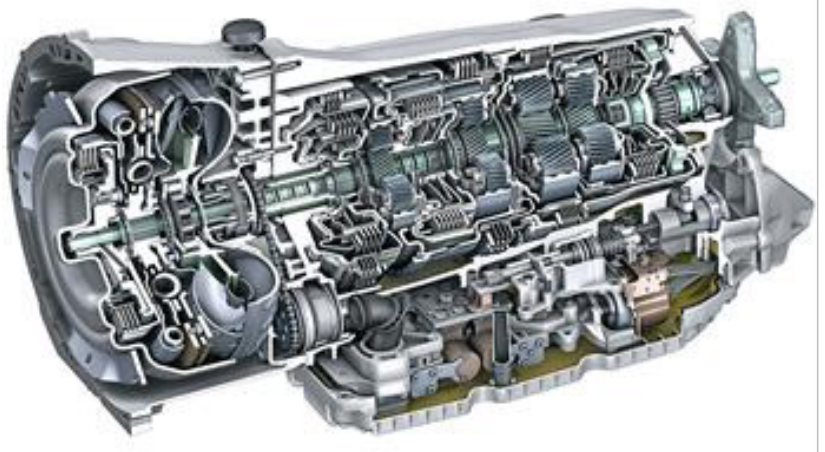

Fig. 4. 9-speed automatic transmission, with planetary gears [12].

Further on, there will be presented the results regarding the noise values, achieved on assembly test benches, for each case. 


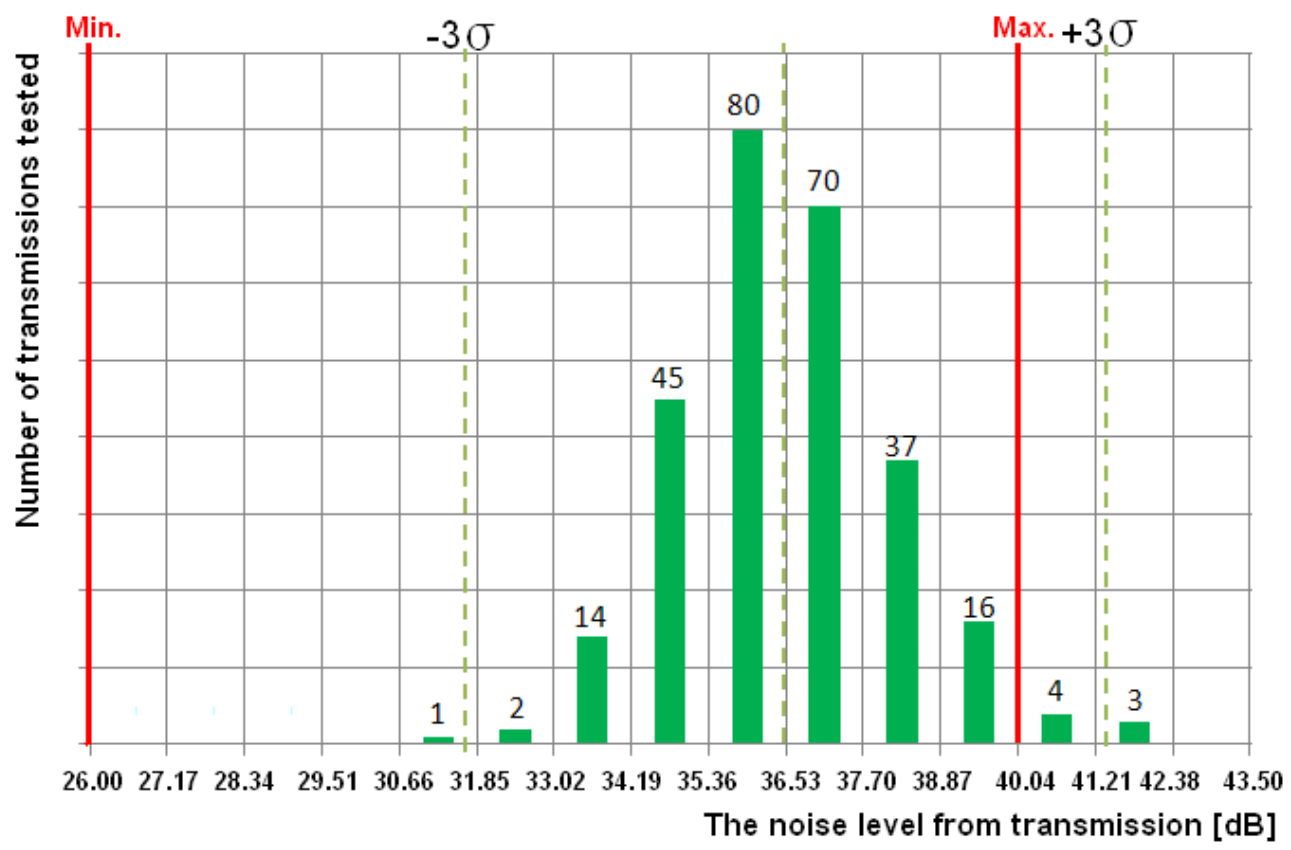

Fig. 5. Case 1 - noise results achieved with $\mathrm{fH} \alpha$ and $\mathrm{fH} \beta$ not optimized, in $\mathrm{dB}$.

As it can be seen in figure 5, there have been tested 272 transmissions; 7 pieces have exceeded the limit of $40 \mathrm{~dB}$, with an average of $36.53 \mathrm{~dB}$, minimum value is $31.54 \mathrm{~dB}$, maximum value is $41.54 \mathrm{~dB}$; scrap rate in this case is $2.57 \%>1 \%$ maximum percentage allowed.

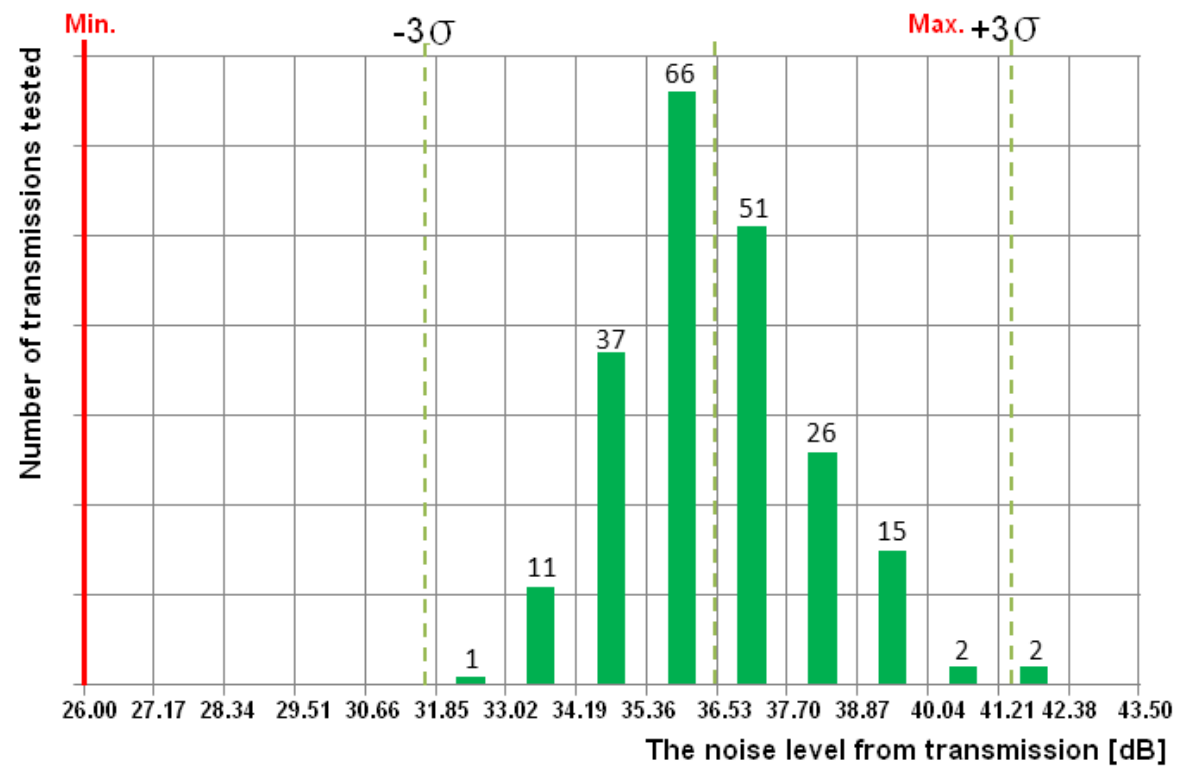

Fig. 6. Case 2 - noise results achieved only with $\mathrm{fH} \beta$ optimized, in $\mathrm{dB}$.

Applying the case number 2, there have been tested 211 transmissions, 4 pieces have exceeded the limit of $40 \mathrm{~dB}$, the average is $36.53 \mathrm{~dB}$ and minimum value is $31.62 \mathrm{~dB}$, 
maximum value is $41.62 \mathrm{~dB}$; scrap rate in this case is $1.89 \%$. All these can be observed in figure 6 .

Results achieved when applying the case number 3, when both parameters, $\mathrm{fH} \alpha \& \mathrm{fH} \beta$ have been optimized, are much better, as can be noticed in figure 7. Practically, there have been tested 593 transmissions, 1 piece has exceeded the limit, the average of registered values is $35.58 \mathrm{~dB}$, minimum registered value is $30.88 \mathrm{~dB}$ and maximum is $40.28 \mathrm{~dB}$. Considering these values, the scrap rate is $0,17 \%<1 \%$ maximum allowed.

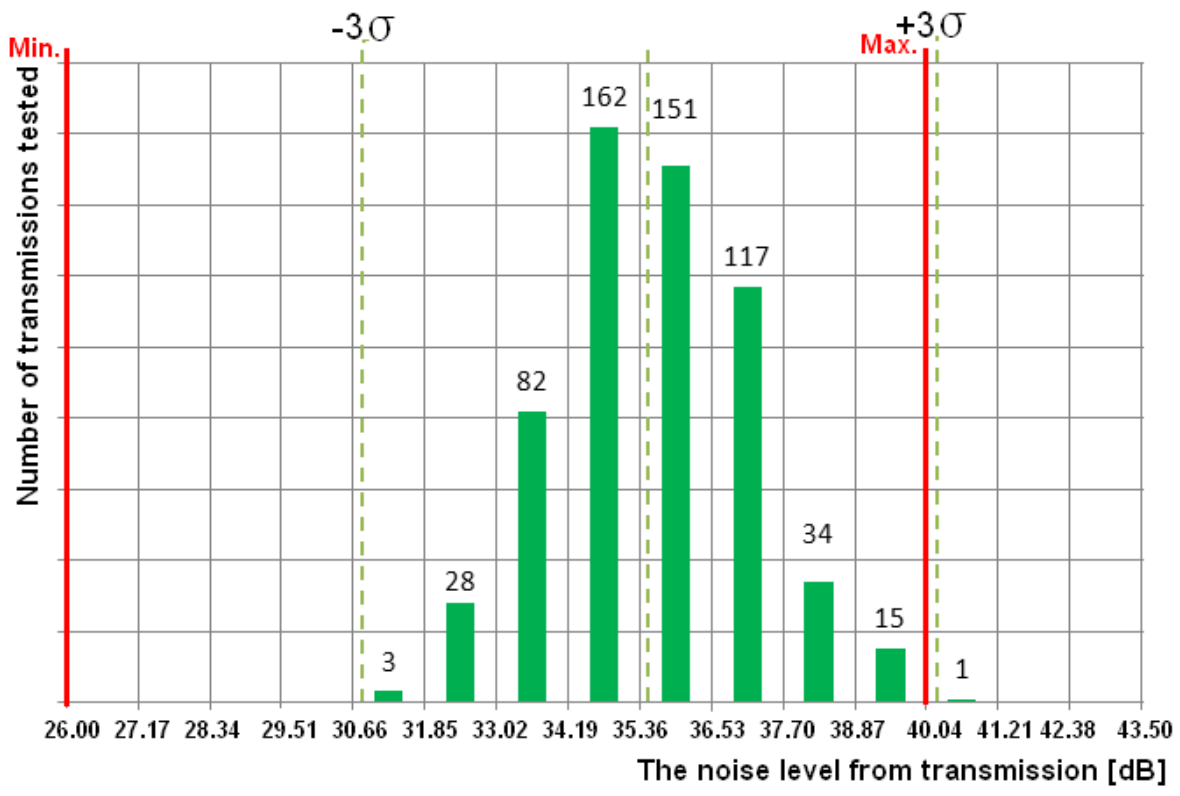

Fig. 7. Case 3 - noise results achieved with $\mathrm{fH} \alpha$ and $\mathrm{fH} \beta$ optimized, in $\mathrm{dB}$.

Further on, there are presented also the effective values of these two parameters, $\mathrm{fH} \alpha$ according to figure 8 and $\mathrm{fH} \beta$ according to figure 9, measured on a Klingelnberg P26 gear measuring equipment. Klingelnberg P26 is measuring equipment used to inspect cylindrical gears, pinion type cutters and shaving cutters, worms and worm wheels, hobs, bevel gears, general dimension, shape, and positional deviations of axially symmetrical workpieces, cam and camshaft measurement and rotor measurement.
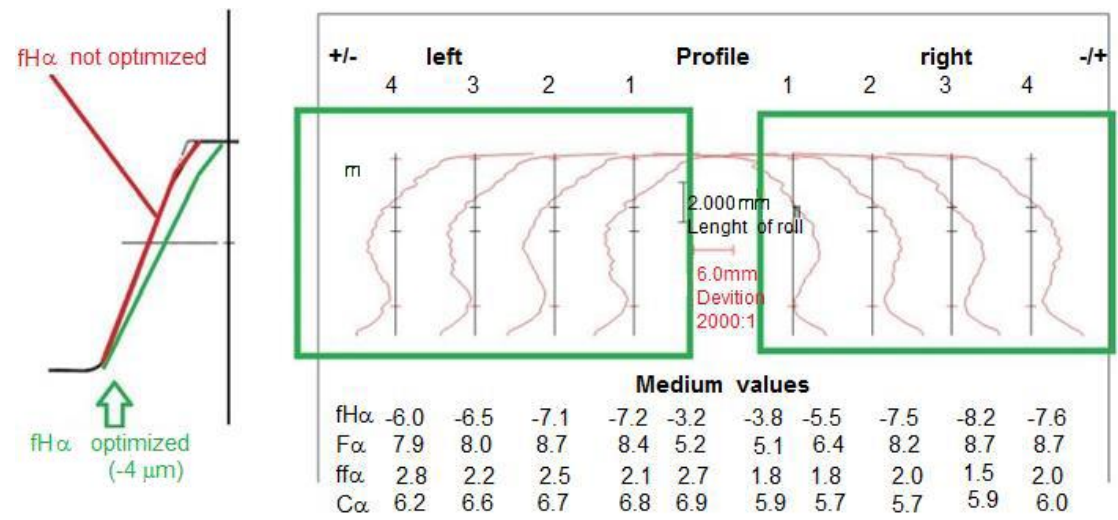

Fig. 8. Values measured for optimized $\mathrm{fH} \alpha$. 
Figure number 8 shows some values achieved for profile angle deviation, when measuring on Klingelnberg P26 equipment, after an adjustment of 4 microns in minus has been applied, as to get a smoother gearing process with matting gears, especially with sun gears. In figure number 8 , there are presented some values for tooth trace angle deviation $\mathrm{fH} \beta$, so it can be seen that the medium values are positive, according to the limits specified in table 4, within chapter 3.

Basically, in this case, it has been set the asymmetrical machining principle, on the left and right flank, while manufacturing the gear on Gleason P90 machines. For each case apart, the scrap rate has been calculated, only when applying the fine adjustment for both parameters, this value could be reduced under $1 \%$, the maximum limit allowed.

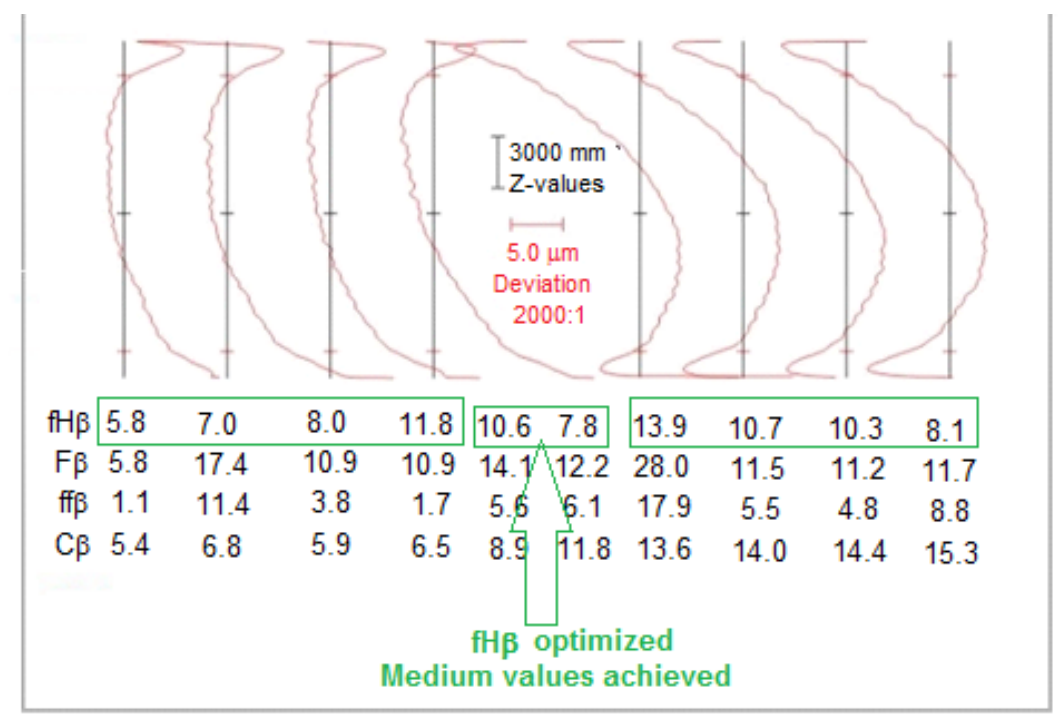

Fig. 9. Values measured for optimized $\mathrm{fH} \beta$.

\section{Conclusions}

This paper highlighted how the fine adjustment of these 2 parameters, $\mathrm{fH} \alpha$ and $\mathrm{fH} \beta$, influences the noise level through gearing process, of an automatic transmission tested on a test bench. There have been identified 3 different cases, as specified above, within chapter 3 , the results achieved have been presented within chapter 4 , for each case apart. Concluding on those facts presented above, it can be noticed, such as follows:

- The noise level depends on quality not only of planetary gears, but of the other matting gears, as well, precisely ring gears and sun gears;

- Even if the quality of planetary gears as individual parts is good, the most important is the result from the end of assembly process;

- When applying the first case, the scrap rate was $2.57 \%$, much more than $1 \%$, the maximum value allowed;

- Considering the second case, the value for scrap rate was $1.89 \%$, better in this case, but still needed to be further optimized;

- When applying the third case, the target has been reached, less than $1 \%, 0.17 \%$ precisely;

- This research is a base for further trials that could be further performed, if such problems may occur. 
As presented above, these main conclusions have been stated as being the key features when discussing the results achieved, presented above. These results have been achieved applying this experimental methodology and can be further used and extended if needed, if the problem appears while testing the run-off cycle. This study might be considered as a smaller technical source of know-how for similar challenges that have to be passed when speaking about NVH topics, especially for automatic transmissions.

\section{References}

1. J. A. Speck, Mechanical Fastening, Joining, and Assembly, 2nd Edition, (CRC Press, Taylor by Francisc Group, 2015)

2. Ih. Jeong-Guon, C.-Y. CHOI, T.-K. KIM, S.-H. JANG, H.-J. KIM, International Journal of Automotive Technology 12(4), 617-630 (2011)

3. P.M. Suresh, Estimation of noise and vibration (nvh) of the sandwich constructed component of the automotive vehicle, (Ph.D Thesis at Kuvempu University, India, 2009)

4. T. Eritenel, R. G. Parker, Journal of Sound and Vibration 331(15), 3628-3648 (2012)

5. Y. Guo, T. Eritenel, T. M. Ericson, R. G. Parker, Journal of Sound and Vibration 333 (22), 5762-5785 (2014)

6. G. D'Elia, E. Mucchi, M. Cocconcelli, Mechanical Systems and Signal Processing 83, 305-320 (2017)

7. D. Ibarra, R. Ramírez-Mendoza, E. López, Applied Acoustics 118, 58-65 (2017)

8. G. Sheng, Vehicle Noise, Vibration, and Sound Quality, (SAE International, 2012)

9. *** https://en.wikipedia.org/wiki/Noise,_vibration,_and_harshness

10. *** http://www.powerlinkpt.com/wp-content/uploads/2017/02/powerlink-slide-en05.png

11. DIN 3962, Toleranzen für Stirnradverzahnungen.

12. $* * *$ http://www.car-engineer.com/9g-tronic-automatic-transmission-mercedes/ 